\title{
Dynamics of malaria vector indices in two vegetation zones within North Eastern Adamawa State, Nigeria
}

\author{
Wahedi, J.A. ${ }^{1,2^{*}}$, Ande, A.T. ${ }^{2}$, Oduola, A.O. ${ }^{2}$, Obembe, A. ${ }^{3}$, Tola, M. ${ }^{4}$, Oyeniyi, T.A. ${ }^{4}$ and Awolola, T.S. ${ }^{4}$ \\ ${ }^{1}$ Department of Zoology, Adamawa State University, Mubi, Nigeria \\ ${ }^{2}$ Department of Zoology, University of Ilorin, Ilorin, Nigeria \\ ${ }^{3}$ Department of Biosciences and Biotechnology, Kwara State University, Malete, Nigeria \\ ${ }^{4}$ Molecular Entomology and Vector Control Research Laboratory, Nigerian Institute of Medical Research, \\ Yaba, Lagos, Nigeria \\ *Corresponding author e-mail: wahedijasini@gmail.com \\ Received 10 March 2020; received in revised form 12 June 2020; accepted 15 June 2020
}

\begin{abstract}
Studies profiling community and zonal malaria entomological risk indices are required to identify high risk areas where targeted control resources are most needed or likely to have the greatest impact on reducing risk of malaria infection. This study presents a first report on malaria vector risk indices in two vegetation zones within Adamawa state, Nigeria. Endophilic mosquitoes were collected for one year in selected communities in the Guinea and Sudan savanna zones within the State. Plasmodium falciparum Sporozoite and human blood meal ELISA assays were carried out on the female Anopheles mosquitoes collected. Sibling species composition of the An. gambiae complex were determined using PCR assays. Mean numbers of mosquitoes in the Guinea savanna communities were significantly $(\mathrm{t}=7.73, \mathrm{DF}=11, \mathrm{p}<0.001)$ higher than the Sudan. Man-biting rates $(\mathrm{F}=2.76$, $\mathrm{p}=0.13$ ) of Anopheles mosquitoes were higher in the Guinea but not significantly different from Sudan savanna. Sporozoite rates of mosquitoes within the Guinea savanna were 2.7 times higher than the Sudan. The predominant Anopheles coluzzii species encountered in the state had higher overall human blood indices (0.63) and sporozoite rates (6.9\%) compared to An. gambiae $(0.39,1.9 \%)$ and An. arabiensis $(0.58,2.3 \%)$ respectively. Overall annual human blood indices (0.59) of mosquitoes in Adamawa were lower compared to reports from other States. Prevalence and higher transmission risks indices of endophilic An. coluzzii mosquitoes reveal the need for LLIN and management of relatively permanent An. coluzzii breeding sites in the State. Widespread cattle rearing lifestyle and lower human blood indices of mosquitoes in the study area suggest the need to investigate cattle blood indices of the mosquitoes in the state. Higher entomological risk indices in the Guinea Savanna zone provide baseline information for prioritization of malaria vector control supplies within the State.
\end{abstract}

\section{INTRODUCTION}

Evidences of reductions in malaria disease burdens have been reported especially within the last decade. Between 2010 and 2018, malaria case incidence levels reduced by 70 and $22 \%$ in the WHO South-East Asia and the African Regions respectively (WHO, 2019). The global decline in malaria disease burdens have been linked partly with the deployments of malaria vector control tools such as long-lasting insecticidal nets (LLINs) and indoor residual spray (IRS). In Nigeria, where the highest (25\%) global malaria burden occurs (WHO, 2019), LLIN distribution campaigns and pockets of IRS implementations have been ongoing since 2009 . Consequently, the Nigerian population at risk sleeping under an insecticide-treated net (ITN) or protected by IRS have increased by at least $20 \%$ with a corresponding $20-40 \%$ decrease in malaria mortality rate between 2010 and 2015 (WHO, 2016). While the global search for new vector control tools continues, current gains can be sustained through informed localized interventions guided by 
the knowledge of malaria entomological indices (WHO, 2013). Since intervention effects vary in space as driven by local endemicity levels, studies profiling community and regional malaria entomological risk indices are required to identify high risk areas where targeted strategies and resources are most needed or likely to have the greatest impact on reducing risk of malaria infection (Giardini et al., 2014). These kinds of studies are crucial to the sustenance and furtherance of the recorded malaria reduction rates which is already slowing down and has remained at similar levels between 2014 and 2018 (WHO, 2019). Intra-regional and country variations in malaria entomological indices have been reported across sub-Saharan Africa (Daygena et al., 2017; Ototo et al., 2015; Walker et al., 2013; Oduola et al., 2012; Kigadye et al., 2011; Tchuinkam et al., 2010). However, in Nigeria, much of the malaria vector risk indices data have been generated from the South Western part of the Country (Awolola et al., 2002; Oyewole et al., 2007; Oyewole et al., 2010; Oduola et al., 2013) leaving out other regions such as the North East where only few longitudinal studies involving proper characterization of malaria vector samples, using standard methods, have been reported (Yoriyo et al., 2014; Samdi, 2012). Adamawa is a unique North Eastern State representing one of the largest States in Nigeria. Some of its peculiarities include the presence of both Guinea and Sudan Savanna areas and the prevalence of flood plains with many rivers passing through the Fadama lands all over the State especially during the rainy season (Adewumi, 2013). Despite the foregoing and the data confirming Adamawa as the State with the highest malaria prevalence rate (55.5\%) in the North Eastern region of Nigeria (NMEP, 2016), there has been no report, to our knowledge, on malaria vector risk indices in the different vegetation zones within the State. Such reports are necessary for successful planning, implementation and assessments of effective malaria vector control programmes within the State in order to contribute to the reduction of the malaria burden in the country. This study presents a first report on malaria vector indices across selected communities within the two vegetation zones in Adamawa state, Northeastern Nigeria.

\section{MATERIALS AND METHODS}

\section{Study area and design}

Adamawa State is one of the largest states in Nigeria, with about $38,700 \mathrm{~km}^{2}$ land area and an estimated human population of 4,502,132 (NIPC, 2020). It is located in North Eastern Nigeria with major vegetation formations comprising Guinea and Sudan Savannas (NIPC, 2020). Annual rainfalls in the Sudan (700mm-900mm, 3-4 months), Southern (1100mm-1600mm, 6-7 months) and Northern (900-1100mm, 4-5 months) Guinea Savanna zones of the state last for about three to seven months respectively (Akosim et al., 1999). The wettest months are August and September while the dry season starts in November and ends in April (Adebayo, 1999). Relative humidity is usually very low (20-30\%) between January and March with increase as from April to a maximum of $80 \%$ in August and September (Adebayo, 1999). Adamawa is one of the Nigerian States with very high concentration of livestock, the most significant being the 3.5 million Adamawa gudali cattle managed in relatively small herd sizes by settled pastoralists who rarely move very far but send their cattle to favourable locales at the peak of the dry season (Tukur and Ardo, 1999). Four communities were selected on the basis of proximity to similar river tributaries which may form suitable breeding habitats for Anopheles mosquitoes (Table 1). Two of the communities (Bazza and Vimtim) are located in the Sudan Savanna while the other two (Imburu and Bachure) belong to the Northern Guinea Savanna zone, hereafter referred to as Guinea Savanna zone. The communities had houses without major barriers (ceilings and window nets) to mosquito entry and were similar in that some of the residents were settled pastoralists engaging in extensive cattle management systems. The community residents all lacked LLINs probably because of the long interval between the last LLIN 
Table 1. Description of study communities in the two vegetation zones in Adamawa State

\begin{tabular}{lccc}
\hline Vegetation Zone & Community & River tributaries present & Coordinates \\
\hline Sudan Savanna & Bazza & Yedsaram & $10^{\circ} 33.50 \mathrm{~N}, 13^{\circ} 23.00 \mathrm{E}$ \\
Sudan Savanna & Vimtim & Yedsaram & $10^{\circ} 23.50 \mathrm{~N}, 13^{\circ} 21.00 \mathrm{E}$ \\
Guinea Savanna & Bachure & Benue & $09^{\circ} 16.50 \mathrm{~N}, 12^{\circ} 24.50 \mathrm{E}$ \\
Guinea Savanna & Imburu & Benue & $09^{\circ} 30.00 \mathrm{~N}, 11.5^{\circ} 20.00 \mathrm{E}$ \\
\hline
\end{tabular}

distribution campaign in the State in 2010 and the period of the study in 2016.

\section{Endophilic mosquito collection and identification}

Indoor resting mosquitoes were collected monthly between January and December, 2016 from ten rooms in each of the four communities using pyrethrum spray collection method. The room chosen in each house were used throughout the study. Each room was selected only if the occupants affirmed readiness to allow the use of the rooms throughout the period of the study. The number of persons that slept in each room over the night before mosquito collection was recorded for man-biting rates estimations (Shililu et al., 1998; WHO 2003). Each female mosquito sample collected was preserved on silica gel in $1.5 \mathrm{ml}$ Eppendorf tube for further analysis at The Nigerian Institute of Medical Research, Lagos. All samples were identified morphologically (Gillies and Coetzee, 1987) before species-specific PCR (Scott et al., 1993) and PCR-RFLP (Favia et al., 1997) assays were conducted on $98 \%(161 / 164)$ and $95 \%(437 / 458)$ of the female An. gambiae s.l collected in Sudan and Guinea Savanna zones respectively.

\section{Determination of $P$.falciparum infection and presence of human blood in mosquitoes}

Plasmodium falciparum sporozoite ELISA (Wirtz et al., 1987) were conducted on heads-thoraces of all collected female $A n$. gambiae (s.l.) samples using monoclonal antibodies and positive controls from Centers for Disease Control and Prevention (Atlanta, USA). Human blood meal ELISA (Beier et al., 1988) carried out on all blood-fed and half-gravid samples were done using human serum and monoclonal antibodies obtained respectively from Rockland immunochemicals (Gilbertsville, USA) and Kikergaard and Perry Laboratories (Gaithersburg, USA).

\section{Data analyses}

Recorded number of persons in the rooms was taken as a reflection of human availability for mosquito bites since the community residents were not sleeping under bed-nets. Proportion of blood-fed and half-gravid samples found with human blood was taken as Human blood index (HBI). Man-biting rates (MBR) were estimated as the number of blood-fed and half-gravid samples collected divided by the number of persons who slept in the rooms over the night before mosquito collection multiplied by HBI (Shililu et al., 1998; WHO 2003). Data obtained were transformed $[\sqrt{ } \mathrm{n}+0.5]$ (Ogbeigbu, 2005) to normal distribution. Mean numbers, human blood indices and man-biting rates of female Anopheles gambiae (s.l.) mosquitoes collected monthly in the two communities per zone were pooled and compared between the two zones. The Proportional data (HBI and MBR) were compared by logistic regression while mean numbers of mosquitoes were compared using Student's t-test (SPSS 16 software) at $\mathrm{p}<0.05$.

\section{RESULTS}

Numbers of female Anopheles mosquitoes collected monthly from the Guinea and Sudan savanna communities are presented in Table 2. Highest numbers of female 


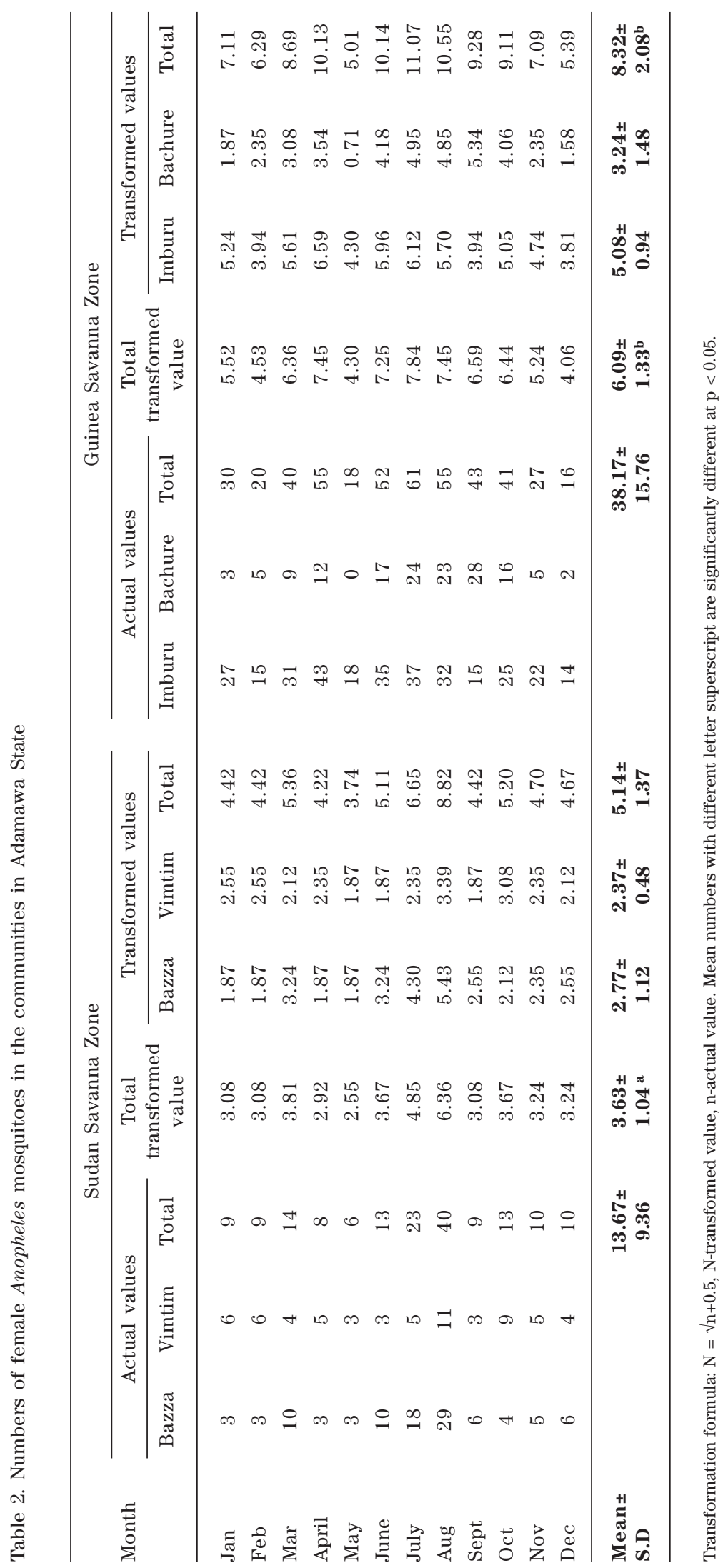


Anopheles mosquitoes were collected in both zones between the month of June and August. A total of 458 (Mean $38.17 \pm 15.76$ ) female Anopheles mosquitoes was collected in the Guinea savanna compared to 164 (Mean 13.67 \pm 9.36 ) mosquitoes found in the Sudan savanna zone (Table 2). Mean numbers of female Anopheles mosquitoes collected in the two Sudan savanna communities were not significantly $(\mathrm{t}=1.329, \mathrm{DF}=11, \mathrm{p}=$ 0.211) different from each other. However, significant differences $(\mathrm{t}=4.680, \mathrm{DF}=11$, $\mathrm{p}=0.001$ ) were found between the numbers of female Anopheles collected in the two communities within the Guinea savanna zone of the state (Table 2).

Transformed mean of the total numbers of female Anopheles in the Guinea savanna zone $(6.09 \pm 1.33)$ was significantly $(\mathrm{t}=$ $7.731, \mathrm{DF}=11, \mathrm{p}<0.001$ ) higher than that of mosquitoes in the Sudan savanna $(3.63 \pm 1.04)$ zone (Table 2$)$. Between the two communities in each zone, the mean man-biting rates of Anopheles mosquitoes were not significantly different (Guinea $\mathrm{F}=$ $0.045, \mathrm{p}=0.837$; Sudan $\mathrm{F}=1.685, \mathrm{p}=0.223$ ).

Mean man-biting rate of mosquitoes in the Guinea savanna $(1.27 \pm 0.57)$ was higher compared to $0.51 \pm 0.38$ in the Sudan savanna zone (Table 3).
Transformed mean man-biting rates of Anopheles mosquitoes were higher in the Guinea savanna $(1.31 \pm 0.22)$ but not significantly $(\mathrm{F}=2.76, \mathrm{p}=0.13)$ different from the Sudan savanna $(0.99 \pm 0.17)$ zone (Table 3).

Human blood indices and man-biting rates of each Anopheles mosquito species encountered in all the communities are presented in Tables 4 and 5 respectively. Number of blood-fed An. coluzzii mosquitoes in the Guinea savanna (306) was 2.2 times higher than the number of the same species in the Sudan savanna (142) zone (Table 4). However, the number of An. gambiae mosquitoes in the Guinea savanna (89) zone was 5.2 times higher compared to the number of An. gambiae in Sudan savanna (17) zone (Table 3). Similarly, the number of An. arabiensis in the Guinea savanna was far higher (42 times) higher than the number of An. arabiensis in the Sudan savanna zone (Table 4).

Anopheles coluzzii had higher human blood indices and man-biting rates $(0.63$, 0.36) compared to An. gambiae (0.39, 0.05) and $A n$. arabiensis $(0.58,0.03)$ species (Tables 4 and 5). In total, only about half (HBI 0.59) of all Anopheles mosquitoes

Table 3. Man-biting rates of Anopheles mosquitoes in the two zones in Adamawa State

\begin{tabular}{|c|c|c|c|c|c|c|c|c|}
\hline \multirow{3}{*}{ Month } & \multicolumn{4}{|c|}{ Sudan Savanna Zone } & \multicolumn{4}{|c|}{ Guinea Savanna Zone } \\
\hline & \multicolumn{2}{|c|}{ Actual values } & \multirow{2}{*}{ Total } & \multirow{2}{*}{$\begin{array}{l}\text { Transformed } \\
\text { total value }\end{array}$} & \multicolumn{2}{|c|}{ Actual values } & \multirow{2}{*}{ Total } & \multirow{2}{*}{$\begin{array}{l}\text { Transformed } \\
\text { total value }\end{array}$} \\
\hline & Bazza & Vimtim & & & Imburu & Bachure & & \\
\hline January & 0.13 & 0.33 & 0.46 & 0.98 & 0.78 & 0.10 & 0.88 & 1.17 \\
\hline February & 0.07 & 0.23 & 0.30 & 0.89 & 0.47 & 0.14 & 0.61 & 1.05 \\
\hline March & 0.33 & 0.19 & 0.52 & 1.01 & 1.41 & 0.21 & 1.62 & 1.46 \\
\hline April & 0.00 & 0.24 & 0.24 & 0.86 & 1.34 & 0.27 & 1.61 & 1.45 \\
\hline May & 0.25 & 0.06 & 0.31 & 0.90 & 0.39 & 0.00 & 0.39 & 0.94 \\
\hline June & 0.31 & 0.12 & 0.43 & 0.96 & 1.45 & 0.67 & 2.12 & 1.62 \\
\hline July & 0.72 & 0.19 & 0.91 & 1.19 & 1.32 & 0.78 & 2.10 & 1.61 \\
\hline August & 1.00 & 0.54 & 1.54 & 1.43 & 0.89 & 0.65 & 1.54 & 1.43 \\
\hline September & 0.29 & 0.00 & 0.29 & 0.89 & 0.37 & 0.94 & 1.31 & 1.35 \\
\hline October & 0.21 & 0.47 & 0.68 & 1.09 & 0.87 & 0.56 & 1.43 & 1.39 \\
\hline November & 0.13 & 0.12 & 0.25 & 0.87 & 0.83 & 0.21 & 1.04 & 1.24 \\
\hline December & 0.11 & 0.13 & 0.24 & 0.86 & 0.47 & 0.13 & 0.60 & 1.05 \\
\hline Mean \pm S.D & & & $51 \pm 0.38$ & $0.99 \pm 0.17^{\mathrm{a}}$ & & & $.27 \pm 0.57$ & $1.31 \pm 0.22^{\mathrm{a}}$ \\
\hline
\end{tabular}

Transformation formula: $\mathrm{N}=\sqrt{\mathrm{n}}+0.5, \mathrm{~N}$-transformed value, $\mathrm{n}$-actual value. Mean numbers with the same letter superscript are not significantly different at $\mathrm{p}<0.05$. 


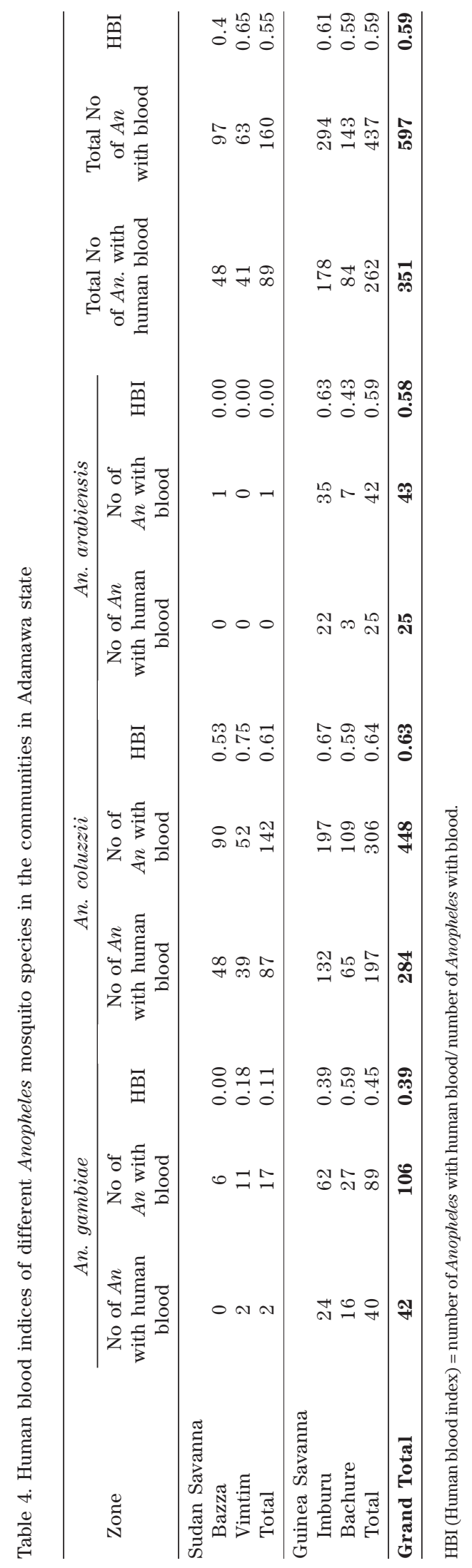

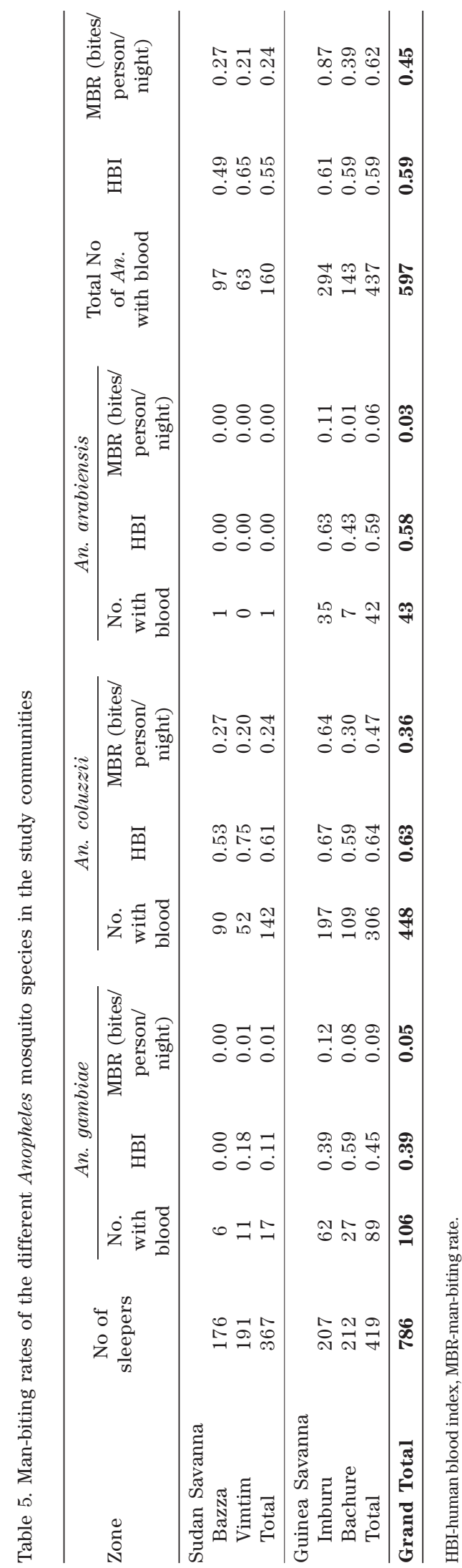


collected from both zones were found with human blood (Table 4).

In both Sudan and Guinea Savanna communities respectively, sporozoite infection rates were higher among the $A n$. coluzzii (2.8\%, 8.8\%) mosquitoes compared to An. gambiae (0\%, 2.2\%) and An. arabiensis $(0 \%, 2.4 \%)$ species (Table 6). Sporozoite infection rates of all the mosquitoes collected in the Guinea Savanna (6.9\%) communities were 2.9 times higher than those of the Sudan savanna (2.4\%) communities (Table 6).

Predominance of An. coluzzii species (88.2\%, 70\%) were observed over $A n$. gambiae $(10.6 \%, 20.4 \%)$ and An. arabiensis $(0.6 \%, 9.6 \%)$ in the Sudan and Guinea Savanna zones respectively (Table 6). Higher occurrences of An. coluzzii ( $\geq 67 \%$ ) compared to An. gambiae ( $\leq 20.9 \%)$ and An. arabiensis $(\leq 15.7 \%)$ were evident in each of the four communities (Table 6).

\section{DISCUSSION}

This study provides information on species composition and entomological risk indices of Anopheles mosquitoes in two vegetation zones within Northeastern Adamawa State, Nigeria. Increased relative humidity between June and August (80\% in August) in Adamawa State (Adebayo, 1999) probably resulted in the collection of higher numbers of mosquitoes within this period across the four communities in the two zones of the State. Significantly higher numbers of mosquitoes found in the communities within the Guinea savanna zone is attributable to longer rainy season period and higher annual rainfall compared to the Sudan savanna zone of the State. Annual mean number of female Anopheles mosquitoes recorded here in the Guinea Savanna areas of Adamawa State compares with earlier reports (Obembe et al., 2018; Obembe et al., 2019) from Kwara, another Guinea Savanna Nigerian State. Similarities in the numbers of female Anopheles mosquitoes collected in the two communities within Sudan Savanna zone of Adamawa State reflects similar climatic conditions in the two communities within the zone. In contrast, significantly higher number of Anopheles mosquitoes in Imburu community compared to the Bachure community within the same Guinea Savanna zone could be due to the higher prevalence of irrigated rice mashed areas providing year round breeding sites for mosquitoes in and around Imburu community.

Predominance of An. coluzzii over An. gambiae in both Guinea and Sudan Savanna communities within Adamawa State is in contrast with the observation of lower $A n$. coluzzii incidence in some Savanna regions of Nigeria (Awolola et al., 2005; Obembe et al., 2018). Both Anopheles coluzzii and An. gambiae mosquito species are known to be naturally anthropophagic and endophilic and therefore considered as very competent vectors in Africa (Gillies and Coetzee 1987; Githeko et al., 1994; Killeen, 2014). However, An. gambiae can better utilize small temporary breeding sites (Gimonneau $e t$ al., 2014) while An. coluzzii prefers flooded relatively permanent breeding sites (Sogoba et al., 2008; Gimonneau et al., 2012). Adamawa State is characterized by flood plains with many rivers passing through the Fadama lands all over the State especially during the rainy season (Adewumi, 2013). These flood plains could have provided the relatively permanent breeding sites preferred by An. coluzzii larvae leading to its prevalence over An. gambiae and An. arabiensis in the four communities considered in this study. Lamidi et al. (2017) have also reported the prevalence of An. coluzzii in another neighboring Northeastern State of Taraba.

Higher occurrence of Anopheles coluzzii among the mosquitoes collected indoors may indicate increased human-vector contact leading to the observations of higher Anopheles coluzzii human blood indices, man-biting and sporozoite rates compared to An. gambiae and An. arabiensis.

Single populations of An. arabiensis species typically breed in ephemeral, sunlit water pools (Kenea et al., 2011) and can exhibit a wide range of behaviours, biting and resting indoors as well as outdoors and feeding on both humans and animals (Githeko et al., 1994; Tirados et al., 2006; Kitau et al., 2012; Mayagaya et al., 2015). Therefore, low 


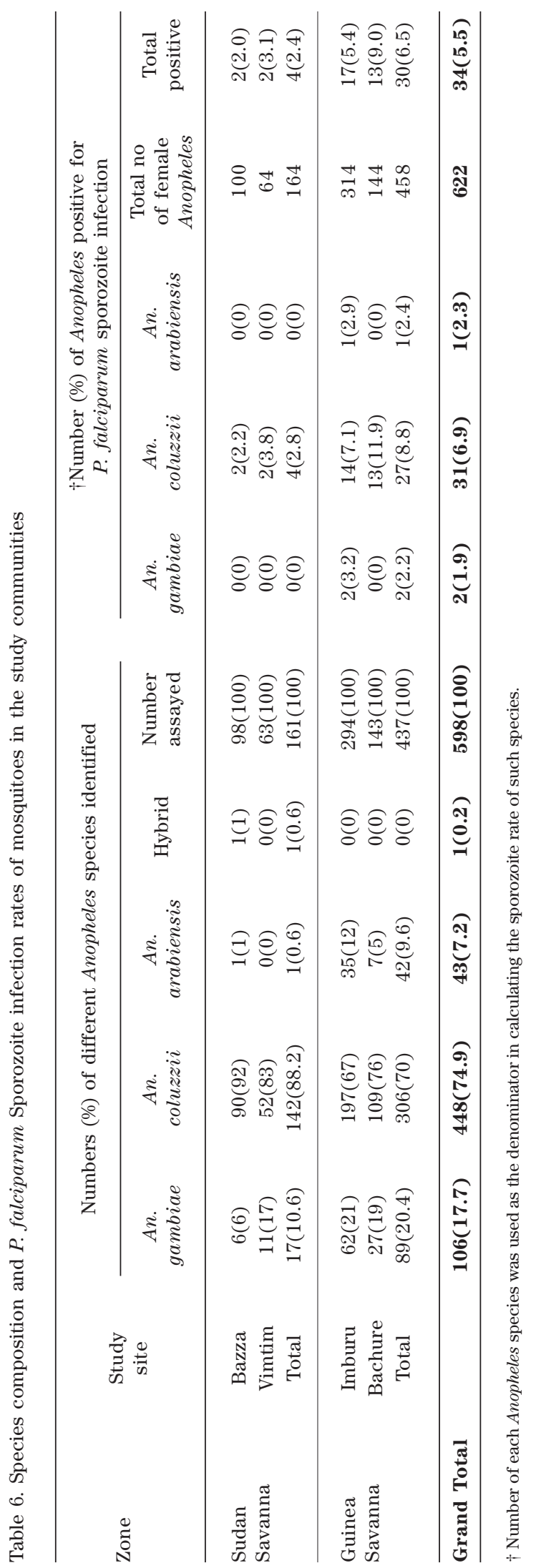


occurrence of indoor resting $A n$. arabiensis mosquitoes in this study could also be due to their zoophilic and exophilic tendencies (Mahande et al., 2007; Mayagaya et al., 2015). This is in consonance with the results of $0.6 \%$ An. arabiensis incidence in two communities in Guinea Savanna area of Kwara State (Obembe et al., 2018). Generally, all the mosquito species had higher numbers in the Guinea savanna compared to the Sudan Savanna zone. However, the difference between the numbers of An. coluzzii mosquitoes found in both zones was low compared to the difference between the numbers of mosquitoes of other species (between An. gambiae and An. gambiae; between An. arabiensis and An. arabiensis) found in both zones. Lower differences in the number of An. coluzzii found in both zones could be as a result of widespread presence of suitable relatively permanent breeding sites (flood plains) available for An. coluzzii development in both zones of the State. However, high differences between the numbers of $A n$. gambiae in both zones and between the numbers of $A n$. arabiensis in both zones is attributable to the higher and longer rainfall resulting in the availability of more small and temporary breeding sites suitable for these two species in the Guinea compared to the Sudan Savanna zone. These high differences in the numbers of $A n$. gambiae and An. arabiensis between the two zones probably led to the highly different human blood indices of An. gambiae and $A n$. arabiensis between the two zones. Higher man-biting and P. falciparum sporozoite infection rates of Anopheles mosquitoes in the communities within the Guinea savanna compared to the Sudan is attributable to the significantly higher Anopheles densities found indoors in the former.

Naturally anthropophagic and endophilic An. coluzzii species, which had favourable breeding sites within our study area and was the most abundant within the human dwellings, exhibited the highest human blood index (0.63). However this An. coluzzii HBI and the overall annual human blood indices of all the Anopheles mosquitoes collected in the State (0.59) were lower compared to those reported in other North Eastern States of Gombe (0.71-1.00 (Yoriyo et al., 2014) and Borno (0.98 (Samdi, 2012). This results remain puzzling because the lower human blood indices recorded could not have resulted from the use of bed-nets since this was not found in the communities. Also, widespread availability of cattle may not have caused this since An. coluzzii are not known to be zoophilic than anthropophilic when both humans and cattle are present. However, indoor insecticide application can induce zoophagic tendencies (Lefevre $e t$ al., 2009; Ndenga et al., 2016) or earlier outdoor biting times (Bayoh et al., 2010; Reddy et al., 2011; Gatton et al., 2013) among previously anthropophagic, endophagic and nocturnal An. gambiae, An. coluzzii and An. funestus species. A common practice found among the community residents in this study area was the use of dried and smoldered leaves and/or freshly hung whole plants as indoor mosquito repellents. As such, a probable reason for the relatively low mosquito human blood indices could be the use of these traditional mosquito repellents driving a sizeable portion of the anthropophilic mosquitoes to subsist on the cattle around the communities. Whether or not this freshly hung or smoldered plants can serve as effective mosquito repellents remains to be investigated. Also, studies on cattle blood indices of the mosquitoes in these areas are required to confirm the subsistence of the mosquitoes on cattle. In addition, studies on the use of improved zooprophylaxis (treating the cattle with recommended doses of appropriate insecticides) could be conducted in these areas to determine the potential of this method in further reducing malaria entomological risk indices in these areas.

This study is limited by the non-collection of outdoor resting mosquitoes in addition to non-determination of cattle blood indices of the indoor resting mosquitoes collected. However, the unavailability and nonutilization of insecticide-treated bed-nets by the community residents, prevalence of cattle as the major animal host within the environment of mosquito collection and non-detection of human blood in about half of the mosquitoes collected, suggest that 
the engorged Anopheles mosquitoes devoid of human blood could be carrying cattle blood meal.

\section{CONCLUSION}

This study revealed variations in entomological risk indices of Anopheles mosquitoes in two vegetation zones within a North-Eastern State of Nigeria. Higher entomological risk indices were observed in the Guinea compared to the Sudan Savanna areas of the State. This provides baseline information for prioritization of supplies in the event of scarce mosquito control resources. Studies of this nature are desirable to guide malaria control programmes according to the peculiarities existing in various areas within a State. Prevalence and higher transmission risks indices of endophilic An. coluzzii mosquito species reveal the need for integrated malaria vector control management involving the reinforcements of LLIN availability and utilization as well as larval source management of the relatively permanent An. coluzzii mosquito breeding sites in the State. Low occurrence of An. arabiensis indoors within these cattle dominated areas calls for investigations on outdoor vector species composition and transmission in these areas. Widespread cattle rearing lifestyle as well as lower human blood indices of Anopheles mosquitoes in these areas as compared to other savanna areas in Nigeria suggest the need to initiate studies on the cattle blood indices of the mosquitoes in this study area. Such studies may assist in determining the suitability of the use of zooprophylactic malaria risk reduction measures such as insecticide-treated cattle in the study area.

Acknowledgements. The authors wish to thank the community residents for their cooperation throughout the period of the study. We appreciate Drs. Alice and Robert Wirtz of the Centres for Disease Control and Prevention, Atlanta, USA, for supplying the sporozoite ELISA reagents.

\section{Competing interests}

None declared.

\section{Authors' contributions}

WJA and ATA conceived the study. AOO, ATA and STA designed the study. WJA and AOO supervised the field study and data collection. TAO, MT, WJA and AO conducted the laboratory studies. AO and WJA collated and analyzed the data. AO drafted the manuscript. All authors read and approved the final version of the manuscript.

\section{REFERENCES}

Adebayo, A.A. (1999). Climate I: Sunshine, temperature, evaporation and relative humidity. In: Adamawa State in Maps, Adebayo, A \& Tukur, A. (editors). Yola: Paraclete Publisher; pp. 20-22.

Adewumi, A.S. (2013). Analysis of land use/ land cover pattern along the River Benue channel in Adamawa State, Nigeria. Academic Journal of Interdisciplinary Studies 2(5): 95-107.

Akosim, C., Tella, I.O. \& Jatau, D.F. (1999). Vegetation and forest resources. In: Adamawa State in Maps, Adebayo, A. \& Tukur, A. (editors). Yola: Paraclete Publisher; pp. 32-35.

Awolola, T.S., Okwa, O., Hunt, R.H., Ogunrinade, A.F. \& Coetzee, M. (2002). Dynamics of the malaria-vector populations in coastal Lagos, south-western Nigeria. Annals of Tropical Medicine and Parasitology 96(1): 75-82.

Awolola, T.S., Oyewole, I.O., Amajoh, C.N., Idowu, E.T., Ajayi, M.B., Oduola, A. \& Coetzee, M. (2005). Distribution of the molecular forms of Anopheles gambiae and pyrethroid knock down resistance gene in Nigeria. Acta Tropica 95(3): 204-209.

Bayoh, M.N., Mathias, D.K., Odiere, M.R., Mutuku, F.M., Kamau, L., Gimnig, J.E., Vulule, J.M., Hawley, W.A., Hamel, M.J. \& Walker, E.D. (2010). Anopheles gambiae: historical population decline associated with regional distribution of insecticide-treated bed nets in western 
Nyanza Province, Kenya. Malaria Journal 9: 62.

Beier, J.C., Perkins, P.V., Wirtz, R.A., Koros, J., Diggs, D., Gargan, T.P. \& Koech, D.K. (1988). Blood meal identification by direct enzyme-linked immunosorbent assay (ELISA), tested on Anopheles (Diptera: Culicidae) in Kenya. Journal of Medical Entomology 25(1): 9-16.

Daygena, T.Y., Massebo, F. \& Lindtjørn, B. (2017). Variation in species composition and infection rates of Anopheles mosquitoes at different altitudinal transects, and the risk of malaria in the highland of Dirashe Woreda, south Ethiopia. Parasites and Vectors 10(1): 343.

Favia, G., Della Torre, A., Bagayoko, M., Lanfrancotti, A., Sagnon, N.F., Touré, Y.T. \& Coluzzi, M. (1997). Molecular identification of sympatric chromosomal forms of Anopheles gambiae and further evidence of their reproductive isolation. Insect Molecular Biology 6(4): 377-383.

Gatton, M.L., Chitnis, N., Churcher, T., Donnelly, M.J., Ghani, A.C., Godfray, H.C.J., Gould, F., Hastings, I., Marshall, J., Ranson, H., Rowland, M., Shaman, J. \& Lindsay, S.W. (2013). The importance of mosquito behavioural adaptations to malaria control in Africa. Evolution 67: 1218-1230.

Giardina, F., Kasasa, S., Sié, A., Utzinger, J., Tanner, M. \& Vounatsou, P. (2014). Effects of vector-control interventions on changes in risk of malaria parasitaemia in sub-Saharan Africa: a spatial and temporal analysis. The Lancet Global Health 2(10): e601-e615.

Gillies, M.T. \& Coetzee, M. (1987). A supplement to the Anophelinae of Africa South of the Sahara. Publication of South African Institute of Medical Research 55: 1-143.

Gimonneau, G., Pombi, M., Choisy, M., Morand, S., Dabiré, R.K. \& Simard, F. (2012). Larval habitat segregation between the molecular forms of the mosquito Anopheles gambiae in a rice field area of Burkina Faso, West Africa. Medical and Veterinary Entomology 26(1): 9-17.
Gimonneau, G., Brossettea, L., Mamaïa, W. Dabiré, R.K. \& Simarda, F. (2014). Larval competition between An. coluzzii and An. gambiae in insectary and semi-field conditions in Burkina Faso. Acta Tropica 130: $155-161$.

Githeko, A.K., Service, M.W., Mbogo, C.M., Atiel, F.K. \& Juma, F.O. (1994). Origin of blood meals in indoor and outdoor resting malaria vectors in Western Kenya. Acta Tropica 58: 307-316.

Kenea, O., Balkew, M. \& Gebre-Michael, T. (2011). Environmental factors associated with larval habitats of anopheline mosquitoes (Diptera: Culicidae) in irrigated and major drainage areas in the middle course of the Rift Valley, central Ethiopia. Journal of Vector Borne Disease 48: 85-92.

Kigadye, E., Nkwengulila, G., Magesa, S.M. \& Abdulla, S. (2011). Spatial variability in the density, distribution and vectorial capacity of Anopheline species in a high transmission district in Tanzania. Tanzania Journal of Health Research 13(4):

Killeen, G.F. (2014). Characterizing, controlling and eliminating residual malaria transmission. Malaria Journal 13: 330.

Kitau, J., Oxborough, R.M., Tungu, P.K., Matowo, J., Malima, R.C., Magesa, S.M., Bruce, J., Mosha, F.W. \& Rowland, M.W. (2012). Species shifts in the Anopheles gambiae complex: do LLINs successfully control Anopheles arabiensis? PLoS One 7: e31481.

Lamidi, B.T., Pukuma, M.S., Qadeer, M.A., Elijah, M.I., Ukwubile, C.A. \& Dairu, F. (2017). Genetic variants, seasonal abundance and man-biting rate of Anopheles gambiae sensu lato in Bali, Taraba State, Nigeria. Nigerian Journal of Parasitology 38(2): 227-232.

Lefevre, T., Gouagna, L.C., Dabire, K.R., Elguero, E., Fontenille, D., Renaud, F., Constantini, C. \& Thomas F. (2009). Beyond nature and nurture: phenotypic plasticity in blood-feeding behavior of Anopheles gambiae s.s. when humans are not readily accessible. American Journal of Tropical Medicine and Hygiene 81: 1023-1029. 
Mahande, A., Mosha, F., Mahande, J. \& Kweka, E. (2007). Feeding and resting behaviour of malaria vector, Anopheles arabiensis with reference to zooprophylaxis. Malaria Journal 6(1): 100.

Mayagaya, V.S., Nkwengulila, G., Lyimo, I.N., Kihonda, J., Mtambala, H., Ngonyani, H. \& Ferguson, H.M. (2015). The impact of livestock on the abundance, resting behaviour and sporozoite rate of malaria vectors in southern Tanzania. Malaria Journal 14(1): 17.

National Malaria Elimination Programme (NMEP), National Population Commission (NPopC), National Bureau of Statistics (NBS), and ICF International. (2016). Nigeria Malaria Indicator Survey 2015: Key Indicators. Abuja, Nigeria, and Rockville, Maryland, USA: NMEP, NPopC, and ICF International. https:// dhsprogram.com/pubs/pdf/MIS20/ MIS20.pdf Accessed March 12, 2020.

Ndenga, B.A., Mulaya, N.L., Musaki, S.K., Shiroko, J.N., Dongus, S. \& Fillinger, U. (2016). Malaria vectors and their bloodmeal sources in an area of high bed net ownership in the western Kenya highlands. Malaria Journal 15: 76.

Nigerian Investment Promotion Commission (2020). Nigerian States: Adamawa State. https://nipc.gov.ng/nigeria-states/ adamawa-state/ Accessed February 15, 2020.

Obembe, A., Popoola, K.O., Oduola, A.O. \& Awolola, S.T. (2018). Mind the weather: a report on inter-annual variations in entomological data within a rural community under insecticide-treated wall lining installation in Kwara State, Nigeria. Parasites and Vectors 11(1): 497.

Obembe, A., Popoola, K.O., Oduola, A.O., Tola, M., Adeogun, A.O., Oyeniyi, T.A. \& Awolola, S.T. (2019). Preliminary evaluation of village-scale insecticidetreated durable wall lining against Anopheles gambiae sl in Akorede, Kwara State, Nigeria. Manila Journal of Science 12: 1-9.
Oduola, A.O., Olojede, J.B., Oyewole, I.O. Otubanjo, O.A. \& Awolola, T.S. (2013). Abundance and diversity of Anopheles species (Diptera: Culicidae) associated with malaria transmission in human dwellings in rural and urban communities in Oyo State, Southwestern Nigeria. Parasitology Research 112(10): 3433-3439.

Oduola, A.O., Otubanjo, J.H., Olojede, J.B., Oyewole, I.O. \& Awolola, T.S. (2012). Malaria transmission risk indices of three Anopheles species in selected rural communities in Oyo State SouthWest Nigeria. International Journal of Tropical Medicine 7(1): 42-48.

Ogbeigbu, A.E. (2005). Biostatistics: a practical approach to research and data handling. Benin City: Mindex Publishing Company Limited; pp. 131.

Ototo, E.N., Mbugi, J.P., Wanjala, C.L., Zhou, G., Githeko, A.K. \& Yan, G. (2015). Surveillance of malaria vector population density and biting behaviour in western Kenya. Malaria Journal 14(1): 244.

Oyewole, I.O., Awolola, T.S., Ibidapo, C.A., Oduola, A.O., Okwa, O.O. \& Obansa, J.A. (2007). Behaviour and population dynamics of the major Anopheline vectors in a malaria endemic area in southern Nigeria. Journal of Vector Borne Diseases 44(1): 56-64.

Oyewole, I.O., Ibidapo, C.A., Okwa, O.O., Oduola, A.O., Adeoye, G.O., Okoh, H.I. \& Awolola, T.S. (2010). Species composition and role of Anopheles mosquitoes in malaria transmission along Badagry Axis of Lagos Lagoon, Lagos, Nigeria. International Journal of Insect Science 2: IJIS-S4698.

Reddy, M.R., Overgaard, H.J., Abaga, S., Reddy, V.P., Caccone, A., Kiszewski, A.E. \& Slotman, M.A. (2011). Outdoor host seeking behaviour of Anopheles gambiae mosquitoes following initiation of malaria vector control on Bioko Island, Equatorial Guinea. Malaria Journal 10: 184 . 
Samdi, L.M. (2012). A study on the malaria vector (Anopheles spp.) in a SudanoSahelian Savannah area of Borno State Northeastern Nigeria and Insect growth regulator pyriproxyfen (S-31183). https://irepos.unijos.edu.ng/jspui. Accessed Feb 20, 2020.

Scott, J.A., Brogdon, W.G. \& Collins, F.H. (1993). Identification of single specimens of the Anopheles gambiae complex by the polymerase chain reaction. The American Jourmal of Tropical Medicine and Hygiene 49(4): 520-529.

Shililu, J.I., Maier, W.A., Seitz, H.M. \& Orago, A. S. (1998). Seasonal density, sporozoite rates and entomological inoculation rates of Anopheles gambiae and Anopheles funestus in a high altitude sugarcane growing zone in western Kenya. Tropical Medicine and International Health 3(9): 706-710.

Sogoba, N., Vounatsou, P., Bagayoko, M.M., Doumbia, S., Dolo, G., Gosoniu, L. \& Touré, Y.T. (2008). Spatial distribution of the chromosomal forms of Anopheles gambiae in Mali. Malaria Journal 7(1): 205.

Tchuinkam, T., Simard, F., Lélé-Defo, E., Téné-Fossog, B., Tateng-Ngouateu, A., Antonio-Nkondjio, C. \& Awono-Ambéné, H.P. (2010). Bionomics of Anopheline species and malaria transmission dynamics along an altitudinal transect in Western Cameroon. BMC Infectious Diseases 10(1): 119.

Tirados, I., Costantini, C., Gibson, G. \& Torr, S.J. (2006). Blood-feeding behaviour of the malarial mosquito Anopheles arabiensis: implications for vector control. Medical and Veterinary Entomology 20: 425-437.

Tukur, A.L. \& Ardo, M.B. (1999). Livestock. In: Adamawa State in Maps, Adebayo, A. \& Tukur, A. (editors). Yola: Paraclete Publisher; pp. 45-47.
Walker, M., Winskill, P., Basáñez, M.G. Mwangangi, J.M., Mbogo, C., Beier, J.C. \& Midega, J.T. (2013). Temporal and micro-spatial heterogeneity in the distribution of Anopheles vectors of malaria along the Kenyan coast. Parasites and Vectors 6(1): 311.

Wirtz, R.A., Zavala, F., Charoenvit, Y., Campbell, G.H., Burkot, T.R., Schneider, I. \& Andre, R.G. (1987). Comparative testing of monoclonal antibodies against Plasmodium falciparum sporozoites for ELISA development. Bulletin of the World Health Organization 65(1): 3945.

World Health Organization. Malaria entomology and vector control. Guide for participants. Geneva: World Health Organization; 2013. https://apps.who. int/iris/bitstream/handle/10665/85890/ 9789241505819_eng.pdf

World Health Organization. Malaria entomology and vector control: Learner's guide. Geneva: World Health Organization; 2003. http://whqlibdoc.who.int/hq/ 2003/WHO-_CDS_CPE_SMT_2002.18_ Rev.1_PartI.pdf.

World Health Organization. World Malaria Report 2016. Geneva: World Health Organization; 2016. http://www.who.int/ malaria/.../world_malaria_report_2016/ wmr2016_full_report.pdf.

World Health Organization. World Malaria Report 2019. Geneva: World Health Organization; 2019. http://www.who.int/ malaria/.../world_malaria_report_2019/ wmr2019_full_report.pdf.

Yoriyo, K.P., Alo, E.B., Napthali, R.S., Samdi, L.M., Oduola, A.O. \& Awolola, T.S. (2014). Anopheles species abundance and vectorial competence in four local government areas of Gombe state Northeast Nigeria. International Journal of Advanced Studies in Engineering and Scientific Inventions 2: 19-25. 